\title{
EFFECT OF CALCIUM CHANNEL-BLOCKERS ON CLINICAL OUTCOMES OF IMPLANT RETAINED OVERDENTURE IN HYPERTENSIVE PATIENTS
}

\author{
Ahmed M. Alam-Eldein*, Emad A. Mabrouk* and Tamer M. Nasr Mostafa*
}

\begin{abstract}
Purpose: Calcium channel-blocking agents are used extensively for the management of hypertension. Gingival overgrowth around natural teeth has been previously reported in the literature with patients taking calcium channel-blocking agents. There are limited scientific documentations illustrating its effects around dental implants. This study compared the effects of Calcium channelblocking agents (Amlodipine) and angiotensin receptor blockers (Valsartan) on dental implants retaining overdentures in hypertensive patients clinically and radiographically after two years of function.
\end{abstract}

Materials and Methods: Twenty completely edentulous male hypertensive patients wearing mandibular overdentures retained by two implants $(3.6 * 12 \mathrm{~mm}$ Dentium Two- piece (Ball type) dental implant, Dentium Implant System, Korea) were included in this study, Patients were equally and randomly divided into two groups, Group (I) were managed by Amlodipine according to their physician to control the hypertension. Group (II) were managed by Valsartan according to their physician to control the hypertension. Each case was evaluated clinically concerning plaque index, gingival index, probing depth and implant stability by using OSSTELL ISQ and radiographically concerning marginal bone loss at baseline (overdenture insertion) and after 6, 12 and 24 months. Data were collected, tabulated and statistically analyzed using t-Student test.

Results: No statistical significant difference was found between the two groups $(\mathrm{P} \geq 0.05)$.

Conclusions: Based on the limitations of the present study and although no statistical difference was found between the effect of Amlodipine and Valsartan on dental implants under overdentures. Peridontium around implants in hypertensive patients managed by calcium channel blockers Amlodipine was affected more than that managed by Valsartan.

KEYWORDS: Dental implant, Hypertension, Overdenture.

* Lecturer, Prosthodontic Department, Faculty of Dentistry, Tanta University. 


\section{INTRODUCTION}

Gingival overgrowth (enlargement, hyperplasia) is benign painless condition, characterized by massive enlargement of the interdental papillae, which can range from mild to extremely severe ${ }^{1,2}$. It may be accompanied by swelling of the gingival margin and partial cover of the occlusal surface of teeth, causing aesthetic limitations and functional difficulties in swallowing, speaking, and mastication $^{1,3}$.

Gingival overgrowth (GO) is usually more conspicuous at labial/buccal surface of both upper and lower anterior teeth ${ }^{4}$. GO can be caused by various factors, such as inflammatory changes, mouth breathing, vitamin $\mathrm{C}$ deficiency, heredity, malignancies, hormonal alterations (seen in puberty and pregnancy), and the adverse effects associated with the systemic administration of certain drugs/ drug induced gingival overgrowth (DIGO) ${ }^{4}$.

The prevalence of the DIGO is 3-20\% compared to other gingival enlargements ${ }^{4}$. DIGO was firstly observed in patients who were taking phenytoin for epilepsy; with approximately 50\% having GO ${ }^{1,5}$. Currently, more than 20 drugs, mainly among anticonvulsants (e.g., phenytoin), immunosuppressants (e.g., cyclosporine A), and various calcium channel blockers (e.g., nifedipine, verapamil, and diltiazem), are associated with gingival enlargements ${ }^{2,6}$.

Hypertension is a crucial risk factor for cardiovascular diseases; the World Health Organization classifies hypertension as "a silent killer" and "a global public health crisis"7, 8 . Hypertension was responsible for $45 \%$ of deaths due to coronary heart diseases and for $51 \%$ of deaths due to stroke. Mortality due to hypertension was reported as 9.4 million annually. Moreover, hypertension was the leading risk factor for death, followed by tobacco use and diabetes mellitus ${ }^{9}$. On the other hand, improvements in diagnosis and follow-up, the presence of numerous options for antihypertensive medication, and an increased awareness and patient participation in treatment in this age of rapid communication are promising developments in the management of hypertension ${ }^{10}$.

The joint guideline by the European Society of Hypertension and the European Society of Cardiology (the 2013 guideline on arterial hypertension) recommends five main drug groups [(diuretics, beta-blockers, calcium channel blockers, angiotensin-converting enzyme inhibitors (ACEIs), and angiotensin receptor blockers (ARBs)] equally in monotherapy together with lifestyle changes, unless any compelling indication ${ }^{11}$.

Valsartan, which is one of the first members of the ARBs group, has been used since 1996 in Europe and since 1997 in the United States of America. It can be combined with hydrochlorothiazide (HCTZ), amlodipine, and aliskiren. The efficacy and reliability of valsartan in hypertension, postmyocardial infarction, and heart failure have been revealed by large clinical trials ${ }^{12,13,14}$.

Among calcium channel blockers, the dihydropyridines (e.g., nifedipine, felodipine, amlodipine, nitrendipine, nicardipine, and manidipine) tend to be more commonly associated with gingival enlargement ${ }^{6}$.

Amlodipine is a third generation dihydropyridine calcium channel blocker that is frequently used in therapy of hypertension and angina pectoris. The prevalence of GO associated with amlodipine is reported to be $3.3 \%$, which is significantly lower than that associated with nifedipine, ranging from 14 to $83 \%{ }^{15}$.

Complete edentulism affects the psychological, oral, general health and the quality of life. While many patients are satisfied with ordinary complete denture, others prefer implant-retained prostheses ${ }^{16}$.

Complete maxillary and mandibular dentures have been used as a conventional treatment of 
edentulous patients for longer than a century. Suitable complete maxillary dentures are usually well tolerated but many patients struggle to chew and swallow with the complete mandibular denture because it is too unstable. Previous studies have shown that a mandibular two-implant retained overdenture is superior to the conventional denture in terms of retention and stability ${ }^{17}$. Thereby, the two-implant assisted mandibular overdenture should be the first treatment option for mandibular edentulous patients ${ }^{18}$.

Since the exact pathogenesis of amlodipineinduced gingival hyperplasia (AIGO) is not wellunderstood, it has become a serious challenge for the patients and dentists/ periodontists to diagnose and manage the cases effectively. The first line management of AIGO is withdrawal or substitution of amlodipine with the patient's physician consent. Unfortunately, in most of the cases, withdrawal is not possible and drug substitution alone is not enough to overcome the AIGO effects ${ }^{1-4}$.

To date reports related to AIGO are very rare. Majority of available literature are case studies/ presentations which demonstrated that the AIGO occurs within 2-3 months of onset at a dose of 10 $\mathrm{mg} /$ day and rarely within first 6 months of onset at a lower dose of $5 \mathrm{mg} /$ day $^{2}$.

The aim of this study was to compare the effects of Calcium channel-blocking agents (Amlodipine) and angiotensin receptor blockers (Valsartan) on dental implants retaining mandibular overdenture in hypertensive patients clinically and radiographically after two years of function.

\section{MATERIALS AND METHODS}

This study was carried out on twenty completely edentulous, hypertensive male patients with a mean age of 50 years old.

Patient's general health was evaluated by taking full medical history. Laboratory investigations were done to ensure that all selected patients free from any other systemic diseases that might have an effect on implants osseointegration.

Patients were equally and randomly divided into two groups, Group (I) were managed by Amlodipine dose $(5 \mathrm{mg})$ for a period of about 4 years according to their physician to control the hypertension. Group (II) were managed by Valsartan dose (60 mg) for a period of about 4 years according to their physician to control the hypertension.

Patients whose alcoholic, drug abuse, poor oral hygiene were excluded from this study.

Preoperative panoramic radiographs were taken for all patients to show the height of bone in the interforaminal area, the position of the mental foramen and inferior alveolar canal and to check for any clinically undetectable pathology or bone abnormality.

An informed consent approved by the ethics committee was signed by each patient after discussing the treatment plan with them and prior to initiation of treatment.

An acrylic complete denture was fabricated for each patient with the conventional technique using semi-anatomic acrylic teeth set on semi-adjustable articulator. For each patient, two mandibular immediately-loaded $(3.6 * 12 \mathrm{~mm}$ Dentium Twopiece (Ball type) dental implant, Dentium Implant System, Korea) were placed at the anterior region using flapless technique, with ball and socket attachments to retain mandibular overdenture (Figure 1 and Figure 2).

Twenty four hours after implant insertion; patients were recalled and each mandibular denture was relieved at implant locations, the metallic caps were placed on the implants making sure that the dentures were securely seated, the head of each implant was then covered with a small shim to prevent excess acrylic resin from engaging any undercuts. The relieved areas of the fitting surface 


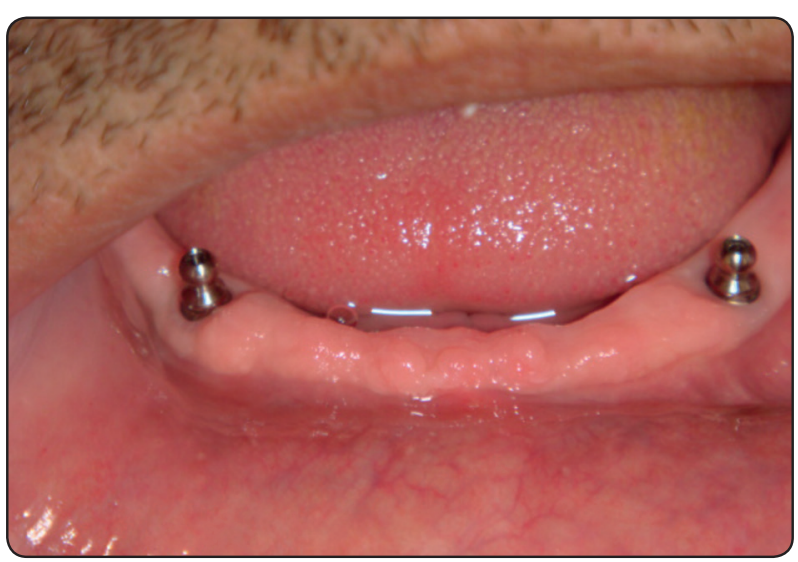

Fig. (1): Clinical picture showing the two implants inserted in the mandibular edentulous arch.

of the denture were filled with autopolymerized acrylic resin, denture was seated and the patient was instructed to bite gently during setting of the acrylic resin. After the resin set, the denture was removed, the metallic caps inside the denture were examined, excess resin trimmed then inserted in patient mouth. Patients were then instructed on how to clean the denture and were asked to return on the following day to examine the denture bearing area and check for signs of tissue irritation. All patients were then scheduled for clinical and radiographic follow-up visits.

Patients were evaluated clinically and radiographically at baseline (complete denture insertion) and at 6,12 and 24 months after complete denture insertion as follows:

\section{Plaque index:}

Plaque adherent to implants' surfaces was quantified at four sites, buccal, lingual, mesial and distal, using a mouth mirror and a plastic dental explorer after air drying of the implant and gingiva. Each of the four areas was scored on a 4-point scale of 0-3 as described by Mombelli and Lang ${ }^{19}$ :

$0=$ No plaque is visible

$1=$ A film of plaque adhering to the free gingival margin and adjacent area of the implant, seen only after application of disclosing solution

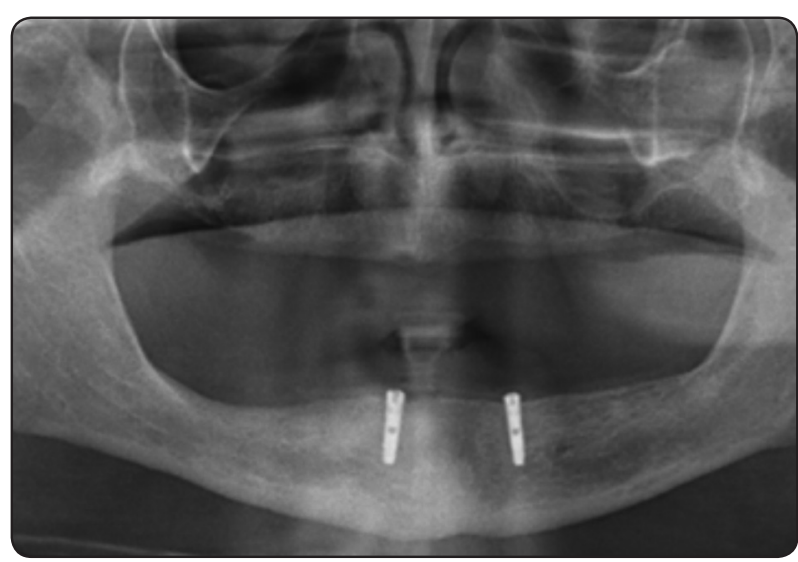

Fig. (2): Radiographic picture showing the two implants inserted in the mandibular edentulous arch.

or by running the explorer across the implant surfaces.

$2=$ Moderate accumulation of soft deposits within the gingival pocket and on the gingival margin and/or adjacent to implant surface that can be seen by the naked eye.

$3=$ Abundance of soft matter within the gingival pocket and/or the gingival margin and adjacent implant surface.

The PI score was obtained by taking the average of the four plaque scores for the single implant.

\section{Gingival index $(\mathbf{G I})^{20}$ :}

The Gingival Index was created for the assessment of the gingival condition and records qualitative changes in the gingiva. It scores the marginal and interproximal tissues separately on the basis of 0 to 3 . The criteria are:

$0=$ Normal gingiva;

$1=$ Mild inflammation - slight change in color and slight edema but no bleeding on probing;

$2=$ Moderate inflammation - redness, edema and glazing, bleeding on probing;

$3=$ Severe inflammation - marked redness and edema, ulceration with tendency to spontaneous bleeding. 
The bleeding is assessed by probing gently along the wall of soft tissue of the gingival sulcus. The scores of the four areas of each implant can be summed and divided by four to give the GI for each implant. The GI of the individual can be obtained by adding the values of each implant surfaces and dividing by the number of each implant examined.

\section{Probing depth ${ }^{21}$ :}

The probing depth was measured using a plastic periodontal probe (CPITN, R.O.R. international, Copenhagen, Denmark) around the surfaces of the implants in four areas (mid-buccal, midlingual, mid-mesial and mid-distal). The score was obtained by taking the average of the four scores for the single implant and. Measurements of probing depth $\leq 1 \mathrm{~mm}$ was recorded as $1 \mathrm{~mm}$, measurements exceeding $1 \mathrm{~mm}$, but less than $2 \mathrm{~mm}$ was recorded as $2 \mathrm{~mm}$, and so on.

Stability test by using OSSTELL ISQ (Osstell Mentor Göteborg, Sweden) ${ }^{22}$ :

$>$ Smart peg was inserted inside the fixture and firmly screwed into it.

$>$ The probe of Osstell was directed toward the smart peg without touching it ( $3 \mathrm{~mm}$ away from it) in two directions bucco- lingual and mesiodistal.

$>$ The average of two readings was calculated .

$>$ Values less than 50 ISQ have a higher risk of failure. An increase in ISQ value during longterm examination implies that the implant became more stable ${ }^{23}$. Reports indicate that ISQ values are proportional to the extent of bone formation ${ }^{24}$.

$>$ Reading above 50 ISQ indicate stable implants (Figure 3).

\section{Periapical and Panoramic radiographs ${ }^{25}$ :}

Periapical and Panoramic X-ray films were used to measure the marginal bone loss around the im-

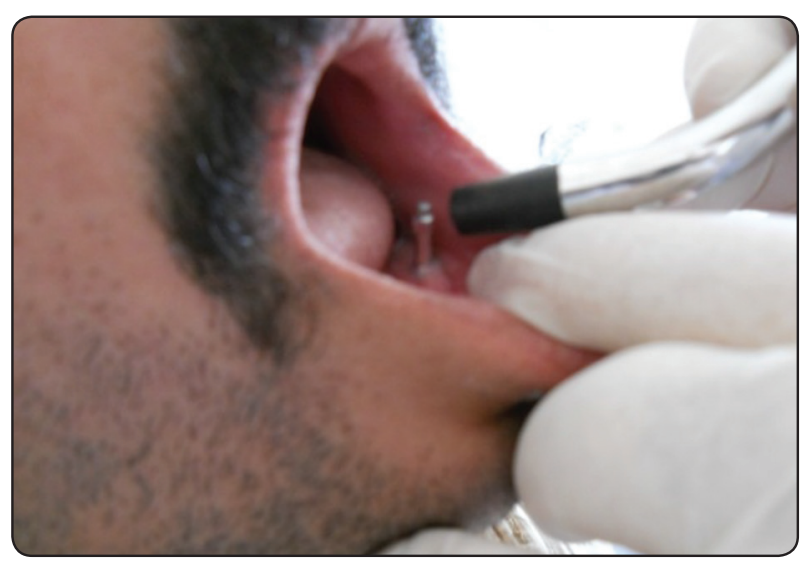

Fig. (3): Stability meter

plants. The long cone paralleling technique using the Rinn XCP instrument (Rinn Co. Dentsply division, York, PA, USA) was used. It included the use of standardized periapical radiographs to detect changes in alveolar bone surrounding the implants during the follow-up period. The standardized periapical radiographs were taken by the Xerograph Coping Process holder with a personalized bite registration record, made from putty rubber base impression material for extension cone $(35 \mathrm{~cm})$ paralleling technique. Every X-ray film was inserted into a slot in the bite-block. To ensure accurate repositioning of the film every time the radiograph was taken, the putty rubber base impression material (Express XT VPS, 3M ESPE AG, Germany) was folded around the bite-block, then a bite registration was obtained for each film in closed mouth position, the putty bite-block with the occlusal registration was kept aside for the follow-up recall visits. Repeatable standardized periapical radiographs were made for each implant to measure the mesial and distal bone heights. The measurements were made from the base of the implant to the most coronal point of bone adjacent to the implant surface.

All radiographs were exposed using ultra speed periapical film (Kodak, Paris, France) with X-ray grid and $\mathrm{X}$ - ray unit set at $70 \mathrm{KV}$ and $10 \mathrm{~mA}$. With similar exposure times, the radiographs were devel- 
oped under standardized condition using automatic process. The scanning settings were adjusted and noted down in order to be used each time with all the radiographs before each scan, 2600 DPI (dot per inch) high quality resolution, 100\% (1:1) scaling, fixed brightness and contrast setting, and no filter or other modifications were selected. The images were displayed on a 17 inches View sonic (3) colored monitor (1024 x 768 DPI). The digital image was then saved in an uncompressed format on the patient file. The stored images of each patient were then interpreted at the end of the follow-up period.

The marginal bone-level measurements were made from the reference point to the lowest observed point of contact of the marginal bone with the fixture. The reference point for the fixture was the fixture-abutment interface. The distance was measured to the nearest $0.01 \mathrm{~mm}$. These measurements were done using an analysis software program (Adobe Photoshop, Adobe Systems Incorporated, San Jose, CA, USA). The actual implant length served as a standard to calculate the bone height, calculations were made according to the following formula:

\section{$\mathrm{CBL}=\mathrm{IL} * \mathrm{BR} / \mathrm{MIL}$}

Where CBL is the calculated bone resorption, IL: Actual implant length, BR: measured bone resorption (mean mesial and distal) and MIL: measured implant length.

\section{Data analysis:}

All clinical and radiographic data were tabulated for each individual and group. Summary statistics (mean, standard deviation) were calculated and also tabulated; data were statistically analyzed using t-Student test.

\section{RESULTS}

\section{Plaque Index:}

Figure (4) shows the mean plaque index values at different periods of follow up and Table (1) lists the results of the t-Student test analysis for plaque index over time. On the initial examination after prosthesis insertion, mean \pm standard deviation (SD) of plaque index scores of group I patients was (4.54 \pm 0.37$)$, while mean \pm standard deviation (SD) of plaque index scores of group II patients was $(4.42 \pm 0.33)$. During the follow-up period there was a non-significant statistical decrease of the plaque index $(\mathrm{P}>0.05)$ between the two groups.

\section{Gingival Index:}

Figure (5) shows the mean gingival index values at different periods of follow up and Table (2) lists the results of the t-Student test analysis for gingival index over time. On the initial examination after prosthesis insertion, mean \pm standard deviation $(\mathrm{SD})$ of gingival index scores of group I patients was $(6.01 \pm 0.26)$, while mean \pm standard deviation $(\mathrm{SD})$ of gingival index scores of group II patients was (5.99 \pm 0.21$)$. During the follow-up period there was a non-significant statistical increase of the gingival index $(\mathrm{P}>0.05)$ between the two groups.

\section{Probing Depth:}

Figure (6) shows the mean probing depth values at different periods of follow up and Table (3) lists the results of the t-Student test analysis for probing depth over time. On the initial examination after prosthesis insertion, mean \pm standard deviation (SD) of probing depth scores of group I and group II patients was $(1 \pm 0)$. During the follow-up period there was a non-significant statistical increase of the probing depth $(\mathrm{P}>0.05)$ between the two groups.

\section{Stability Test (Osstell ISQ):}

Figure (7) shows the stability test values (Osstell ISQ) at different periods of follow up and Table (4) lists the results of the t-Student test analysis for stability test (Osstell ISQ) over time. On the initial examination after prosthesis insertion, mean \pm standard deviation (SD) of stability test scores (Osstell ISQ) of group I patients was 
(55.625 \pm 4.428$)$, while mean \pm standard deviation (SD) of stability test scores (Osstell ISQ) of group II patients was $(56.025 \pm 3.206)$. During the followup period there was a non-significant statistical increase of the stability test values (Osstell ISQ) $(\mathrm{P}>0.05)$ between the two groups.

\section{Marginal bone loss:}

Figure (8) shows the mean marginal bone loss values at different periods of follow up and
Table (5) lists the results of the t-Student test analysis for marginal bone loss over time. On the initial examination after prosthesis insertion, mean \pm standard deviation $(\mathrm{SD})$ of marginal bone loss scores of group I patients was $(0.91 \pm 0.32)$, while mean \pm standard deviation (SD) of marginal bone loss scores of group II patients was $(0.82 \pm 0.28)$. During the follow-up period there was a non-significant statistical increase of the marginal bone loss scores $(\mathrm{P}>0.05)$ between the two groups.

TABLE (1): Comparison of plaque index at different follow up periods.

\begin{tabular}{|c|c|c|c|c|c|c|c|c|}
\hline \multirow{2}{*}{ Plaque Index } & \multicolumn{3}{|c|}{ Group I } & \multicolumn{3}{c|}{ Group II } & \multicolumn{3}{c|}{ T-test } \\
\cline { 2 - 9 } & Mean & \pm & SD & Mean & \pm & SD & t & P-value \\
\hline Insertion & 4.54 & \pm & 0.37 & 4.42 & \pm & 0.33 & 1.63 & 0.413 \\
\hline After 6 Months & 4.24 & \pm & 0.35 & 4.19 & \pm & 0.31 & 1.43 & 0.368 \\
\hline After 12 Months & 3.98 & \pm & 0.34 & 3.88 & \pm & 0.29 & 1.67 & 0.423 \\
\hline After 24 Months & 3.77 & \pm & 0.27 & 3.66 & \pm & 0.25 & 1.35 & 0.493 \\
\hline
\end{tabular}

TABLE (2): Comparison of gingival index at different follow up periods.

\begin{tabular}{|c|c|c|c|c|c|c|c|c|}
\hline \multirow{2}{*}{ Gingival index } & \multicolumn{3}{|c|}{ Group I } & \multicolumn{3}{c|}{ Group II } & \multicolumn{3}{c|}{ T-test } \\
\cline { 2 - 9 } & Mean & \pm & SD & Mean & \pm & SD & t & P-value \\
\hline Insertion & 6.01 & \pm & 0.26 & 5.99 & \pm & 0.21 & 1.66 & 0.439 \\
\hline After 6Months & 6.06 & \pm & 0.32 & 6.04 & \pm & 0.29 & 1.82 & 0.573 \\
\hline After 12Months & 6.11 & \pm & 0.35 & 6.09 & \pm & 0.31 & 1.74 & 0.546 \\
\hline After 24Months & 6.13 & \pm & 0.42 & 6.11 & \pm & 0.39 & 1.78 & 0.483 \\
\hline
\end{tabular}

TABLE (3): Comparison of probing depth at different follow up periods.

\begin{tabular}{|c|c|c|c|c|c|c|c|c|}
\hline \multirow{2}{*}{ Probing Depth } & \multicolumn{3}{|c|}{ Group I } & \multicolumn{3}{c|}{ Group II } & \multicolumn{2}{c|}{ T-test } \\
\cline { 2 - 9 } & Mean & \pm & SD & Mean & \pm & SD & t & P-value \\
\hline Insertion & 1 & \pm & 0 & 1 & \pm & 0 & 0 & 1 \\
\hline After 6Months & 1.37 & \pm & 0.65 & 1.29 & \pm & 0.55 & 1.88 & 0.683 \\
\hline After 12Months & 1.79 & \pm & 0.68 & 1.66 & \pm & 0.57 & 1.64 & 0.389 \\
\hline After 24Months & 1.87 & \pm & 0.87 & 1.71 & \pm & 0.64 & 1.56 & 0.431 \\
\hline
\end{tabular}


TABLE (4): Comparison of implant stability at different follow up periods.

\begin{tabular}{|c|c|c|c|c|c|c|c|c|}
\hline \multirow{2}{*}{ Osstell (ISQ) } & \multicolumn{3}{|c|}{ Group I } & \multicolumn{3}{c|}{ Group II } & \multicolumn{3}{c|}{ T-test } \\
\cline { 2 - 9 } & Mean & \pm & SD & Mean & \pm & SD & t & P-value \\
\hline Insertion & 55.625 & \pm & 4.428 & 56.025 & \pm & 3.206 & 0.168 & 0.869 \\
\hline After 6 Months & 57.75 & \pm & 3.238 & 58 & \pm & 3.424 & 0.072 & 0.943 \\
\hline After 12 Months & 58.075 & \pm & 6.442 & 58.975 & \pm & 5.223 & 0.231 & 0.82 \\
\hline After 24 Months & 60.1 & \pm & 2.768 & 60.2 & \pm & 3.4 & 0.343 & 0.735 \\
\hline
\end{tabular}

TABLE (5): Comparison of marginal bone loss at different follow up periods.

\begin{tabular}{|c|c|c|c|c|c|c|c|c|}
\hline \multirow{2}{*}{ Marginal bone loss } & \multicolumn{3}{|c|}{ Group I } & \multicolumn{3}{c|}{ Group II } & \multicolumn{3}{c|}{ T-test } \\
\cline { 2 - 8 } & Mean & \pm & SD & Mean & \pm & SD & t & P-value \\
\hline Insertion & 0.91 & \pm & 0.32 & 0.82 & \pm & 0.28 & 1.64 & 0.375 \\
\hline After 6 Months & 1.28 & \pm & 0.37 & 1.17 & \pm & 0.32 & 1.85 & 0.259 \\
\hline After 12 Months & 1.59 & \pm & 0.49 & 1.46 & \pm & 0.39 & 1.52 & 0.376 \\
\hline After 24 Months & 1.74 & \pm & 0.57 & 1.61 & \pm & 0.45 & 1.77 & 0.383 \\
\hline
\end{tabular}

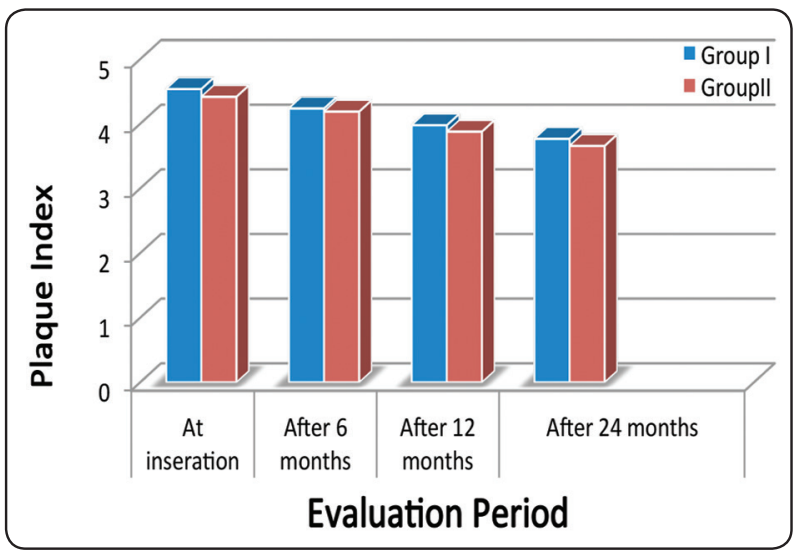

Fig. (4): Distribution of mean value of plaque index between the two groups at different follow up periods.

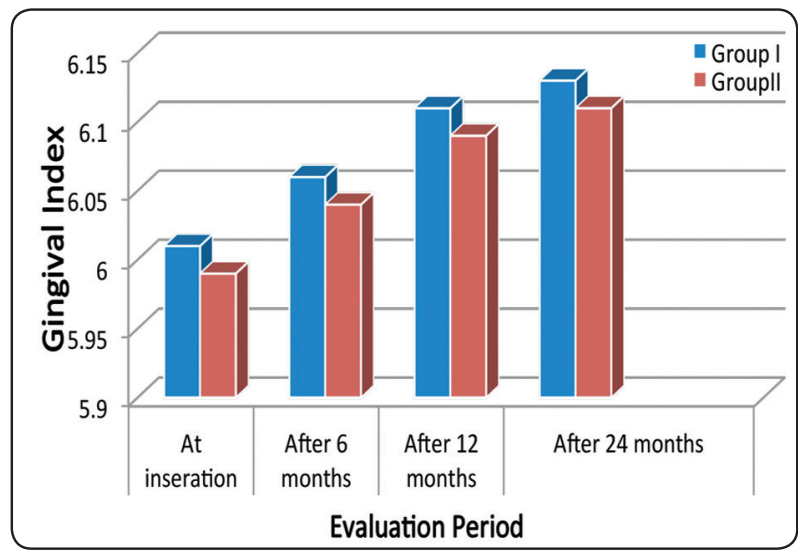

Fig. (5): Distribution of mean value of gingival index between the two groups at different follow up periods. 


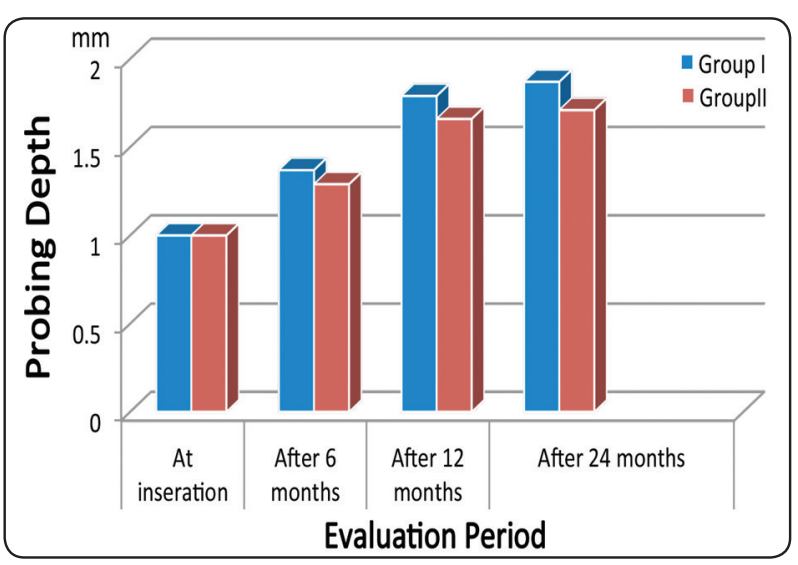

Fig. (6): Distribution of mean value of probing depth between the two groups at different follow up periods.

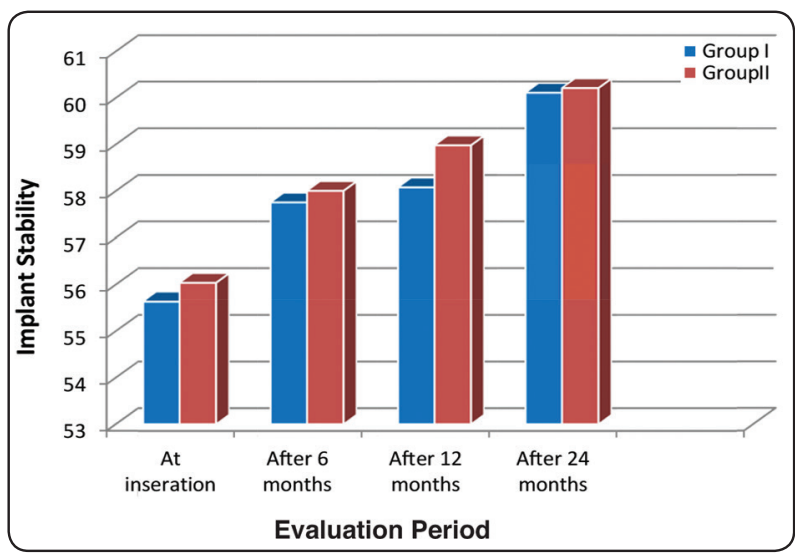

Fig. (7): Distribution of mean value of implant stability between the two groups at different follow up periods.

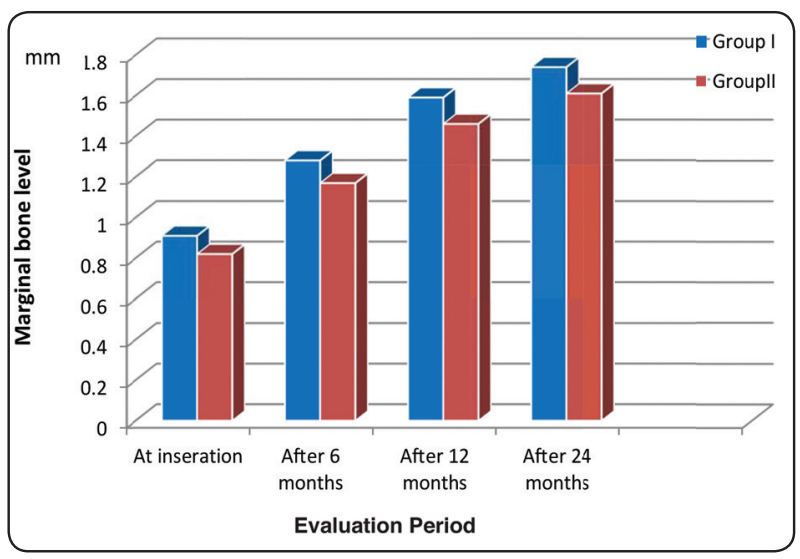

Fig. (8): Distribution of mean value of marginal bone loss between the two groups at different follow up periods.

\section{DISCUSSION}

Today relatively high percentages of elderly population suffer from different cardiovascular diseases and are on permanent antihypertensive therapy. One of the most frequently used drugs is the calcium channel blockers prescribed against high blood pressure. The most common oral side effect of these drugs is the gingival enlargement that might develop even on otherwise healthy gingiva ${ }^{26-28}$.

Usually GO are traps for debris and plaque, causing difficulties in maintenance of oral hygiene, further enhancing secondary inflammation and susceptibility of periodontal disease and caries ${ }^{1-3}$.

Amlodipine is a third generation relatively newer of calcium channel blockers that is frequently used in therapy of hypertension, exhibit adverse effect of gingival enlargement in middle to older aged adults ${ }^{29,30}$. Valsartan is angiotensin receptor blocker used in therapy of hypertension but with no side-effects observed with these calcium channel blockers ${ }^{31,32}$.

In this study, a significant decrease in plaque index was observed over two years of follow-up and may be attributed to routine hygienic recall visits and to the patients' efforts in maintaining a high level of oral hygiene. This matches the results from previous studies which reported successfully osseointegrated implants in patients who followed regular oral hygiene instructions ${ }^{33,34}$.

Slight increase in the gingival index was found in both groups during the follow up period. There is no evidence to support a single factor as responsible for gingival hyperplasia, this may be due to our patients did not have a habit of regular/daily brushing at the beginning of treatment ${ }^{34}$. Further, possible explanation is the fact that our patients were men, and AIGO occurs three times more often in men than in women ${ }^{35}$. Another potential explanation could be a patient's sensitivity to a specific drug's metabolic pathway ${ }^{35}$ or patient's sensitivity to a 
specific amlodipine concentration in the crevicular gingival fluid ${ }^{36}$.

In addition, prosthetic restorations, by movement of the denture base during function which may exert pumping action of the gingival margin. This was decreased after relief in acrylic resin of the overdenture over the inflamed gingival tissue ${ }^{37}$.

Gingival hyperplasia may occur when oral hygiene procedures are discontinued, so plaque accumulation leads to gingivitis in 10-21 days or peri-implant mucositis ${ }^{38,39}$.

There was no significant difference in the gingival index between the two groups. The increases of Amlodipine may be due to that Amlodipine exhibit adverse effect of gingival enlargement in middle to older aged adults ${ }^{29,30}$, but this increase is non-significant, which may be due to lower dose of Amlodipine (5 mg/day) and these results are in agreement with Seymour et al. reported that gingival hyperplasia could be a side effect of amlodipine even with a very short term and low dose administration ${ }^{40}$, or may be due to sharp oral hygiene instruction these is agreed with Thompson et al and Prisant and Herman, where they say drug-induced gingival enlargement can be minimized, but not prevented by meticulous oral hygiene, and regular recall ${ }^{26,41}$.

It was also observed a slight trend of nonsignificant increasing of probing depth around the implants between the two groups during the followup periods, although it did not reach statistical significance. These findings could be attributed to bone resorption during the first year after implant placement; the increases were within acceptable values and are in agreement with previously reported results of a probing depth increase after one year follow-up period and explanation that this phenomenon of up to $1 \mathrm{~mm}$ marginal bone loss is related to maturation of bone after implant placement and adaptation of bone to withstand functional forces ${ }^{42}$.
Implant stability is a critical factor that determines the long-term success of dental implants ${ }^{43}$. In this study, all the Osstell ISQ values are more than 50 and there was insignificant increase in implant stability between the two groups, this was in agreement with Atsumi et $\mathrm{al}^{44}$. On the other hand there was significant increase of implant stability within the same group, this indicates successful Osseointegration ${ }^{45}$.

The difference between the bone loss around the implant fixtures in the two groups was not statistically significant during the follow-up periods.

The difference between the bone loss around the implant fixtures in the two groups was not statistically significant during the follow-up periods. Loss of marginal bone height after the onset of implant function is a phenomenon that is normally observed around dental osseointegrated implants. This has been described as either a plaque- related and/or as a load- related effect ${ }^{46}$.

In this study, crestal bone resorption related to implant abutments in both groups after one year follow-up did not exceed $1 \mathrm{~mm}$, hence all implants were considered successful, this was in agreement with Albrektsson ${ }^{47}$.

Also, this was in agreement with Adell et $\mathrm{al}^{48}$, who found that crestal bone loss around dental implants, typically seen during the first year of implant function was about $1.2 \mathrm{~mm}$ up to the end of the first year of function, and a mean loss of $0.1 \mathrm{~mm}$ annually thereafter. From the study of Albrektsson, success criteria for osseointegrated dental implants were proposed to include a level of marginal bone loss of up to $1.5 \mathrm{~mm}$ in the first year, and then no more than $0.2 \mathrm{~mm}$ annually ${ }^{47}$.

The amount of bone level changes in this study was within the criteria for implant success suggested by Albrektsson and coworkers ${ }^{49}$.

In this study, the use of immediately-loaded flapless one-stage implants without a second surgical 
phase might be a reason of the success rate of the implants. The flapless implant surgery "minimally invasive" preserves maximum amount of blood supply to the bone. On the other hand, reflection of flap in the second stage will compromises part of blood supply coming from soft tissue to bone and interfere with the tissues vascularization ${ }^{50}$.

Due to the limitations of this study, the authors suggest that the small sample size may have affected the power to show a statistical significant change in the clinical and radiographical evaluations. Also longer evaluation period may be needed to asses success of immediately-loaded implants in hypertensive patients.

\section{CONCLUSIONS}

Based on the limitations of the present study and although no statistical difference was found between the effect of Amlodipine and Valsartan on dental implants under overdentures. Dental implants can be immediately loaded successfully to retain mandibular overdentures in controlled hypertensive edentulous patients. Peridontium around implants in hypertensive patients managed by calcium channel blockers Amlodipine was affected more than that managed by Valsartan. Also we need more research about more doses and longer periods.

\section{ACKNOWLEDGMENTS}

We would like to express our appreciation, gratitude and thanks to Prof. Wael Farrag Mohamed professor of internal medicine, Faculty of Medicine, Tanta University. For his efforts in selecting, managing and following up of the patient during the study period.

\section{CONFLICT OF INTEREST}

The Authors declare that they have no conflict of interest, have full control of all primary data.

\section{REFERENCES}

1. Nyska A, Shemesh M, Tal H, Dayan D. Gingival hyperplasia induced by calcium channel blockers: mode of action, Medical Hypotheses 1994;43(2): 115-118.

2. Joshi S, Bansal S. A rare case report of amlodipine induced gingival enlargement and review of its pathogenesis, Case Reports in Dentistry 2013; 2013.

3. Lafzi A, Farahani R, Shoja M. Amlodipine induced gingival hyperplasia Med Oral, Patol Oral Cir Bucal 2006;11(6):480-482.

4. Nishikawa S, Nagata T, Morisaki I, Oka T, Ishida H. Pathogenesis of drug-induced gingival overgrowth. A review of studies in the rat model. J Periodontol 1996; 67(5):463-471.

5. Lawrence DB, Weart CW, Laro JJ, Neville BW. Calcium channel blocker-induced gingival hyperplasia: case report and review of this iatrogenic disease. Journal of Family Practice 1994;39(5):483-488.

6. Srivastava AK, Kundu D, Bandyopadhyay P, Pal AK. Management of amlodipine-induced gingival enlargement: series of three cases, Journal of Indian Soc of Periodontol 2010;14(4):279-281.

7. World Health Organization, Global Status Report on Non communicable Disease 2010. WHO, Geneva, Switzerland 2011.

8. The Ministery of Health, Department of Health Researches, Available at: http://ekutuphane.sagem.gov. tr/kitap.php?id=153\&amp;k=turkey_burden_of_disease_ study 2014.

9. Mendis S, Puska P, Norrving B. World Health Organization in collaboration with the World Heart Federation and the World Stroke Organization. Global atlas on cardiovascular disease prevention and control, Geneva 2011.

10. Kearney PM, Whelton M, Reynolds K, Muntner P, Whelton PK, He J. Global burden of hypertension: analysis of worldwide data. Lancet 2005;365:217-23.

11. Pardell H, Tresserras R, Armario P, Hernandez del Rey R. Pharmaco economic considerations in the management of hypertension. Drugs 2000;59 (2):13-20.

12. Julius S, Kjeldsen S, Weber M, Brunner HR, Ekman S, Hansson L, et al, for the VALUE trial group. Outcomes in hypertensive patients at high cardiovascular risk treated with regimens based on valsartan or amlodipine: the VALUE randomized trial. Lancet 2004;363:2022-31. 
13. McMurray J, Solomon S, Pieper K, Reed S, Rouleau J, Velazquez E, et al. The effect of valsartan, captopril, or both on atherosclerotic events after acute myocardial infarction: an analysis of the Valsartan in Acute Myocardial Infarction Trial (VALIANT). J Am Coll Cardiol 2006;47:726-33.

14. Maggioni AP, Anand I, Gottlieb SO, Latini R, Tognoni G, Cohn JN; Val-HeFT Investigators (Valsartan Heart Failure Trial). Effects of valsartan on morbidity and mortality in patients with heart failure not receiving angiotensin-converting enzyme inhibitors. J Am Coll Cardiol 2002;40:1414-21.

15. Livada R, Shiloah J. Calcium channel blocker-induced gingival enlargement, Journal of Human Hypertension 2014;28(1):10-14.

16. Timmerman R, Stoker G, Wismeijer D, Oosterveld P, Vermeeren JI, van Waas MA. An eight-year follow up to a randomized clinical trial of participant satisfaction with three types of mandibular implant-retained overdentures. J Dent Res 2004;83:630-633.

17. Sadowsky SJ. Mandibular implant-retained overdentures: a literature review. Journal of prosthetic dentistry 2001; $86: 468-73$

18. Aard NJ, Zarb GA. Long-term treatment outcomes in edentulous patients with implant overdentures: the Toronto study. International journal of prosthodontics 2004; $17: 425-33$.

19. Mombelli A, Lang N. Clinical parameters for the evaluation of dental implants. Periodontol 2000. 1994;4:81-86.

20. Loe H, Silness J. Periodontal disease in pregnancy. Acta Odontologica Scandinavica 1963;21:533-55.

21. Akagawa Y, Matsomoto T, Hashimoto M, Tsuru H. Clinical evaluation of the gingival around single crystal sapphire endosseous implant after experimental ligature induced plaque accumulation in monkeys. J Prosthet Dent 1992; 68:111-118.

22. Huang HM, Chiu CL, Yeh CY, Lin CT, Lin LH, Lee SY, Early detection of implant healing process using resonance frequency analysis. Clin Oral Implants Res 2003; 14:437-443.

23. Capek L, Simunek A, Slezak R, Dzan L. Influence of the orientation of the Osstell ${ }^{\circledR}$ transducer during measurement of dental implant stability using resonance frequency analysis: A numerical approach. Med Eng Phys 2009; 31:764-769.
24. Mihoko A, Sang-Hoon P, Hom-Lay W. Methods used to assess implant stability status. The International Journal of Oral \& Maxillofacial Implants 2007;22:743-754.

25. Walters RA. Vertical alveolar bone changes related to overdenture abutment teeth. J Prosth Dent 1987;57:309.

26. Thompson A, Herman W, Konzelman J, Collins M. Treating patients with drug-induced gingival overgrowth. J Dent Hyg 2004 Fall;78(4):12.

27. Walsh $P$, Häkkinen L, Pernu $H$, Knuuttila $M$, Larjava $H$. Expression of fibronectin-binding integrins in gingival epithelium in drug-induced gingival overgrowth. J Periodontal Res 2007 Apr;42(2):144-51.

28. Ellis J, Seymour R, Steele J, Robertson P, Butler T, Thomason J. Prevalence of gingival overgrowth induced by calcium channel blockers: a community-based study. J Periodontol 1999 Jan;70(1):63-7.

29. Pavlic V, Zubovic N, Ilic S, Adamovic T. Untypical amlodipine-induced gingival hyperplasia. Case Rep Dent 2015;2015:756976.

30. Tripathi A, Mukherjee S, Saimbi C, Kumar V. Low dose amlodipine-induced gingival enlargement: A clinical case series. Contemp Clin Dent 2015 Jan-Mar;6(1):107-9.

31. Chioléro A, Burnier M. Pharmacology of valsartan, an angiotensin II receptor antagonist. Expert OpinInvestig Drugs 1998 Nov;7(11):1915-25.

32. Mistry N, Westheim A, Kjeldsen S. The angiotensin receptor antagonist valsartan: a review of the literature with a focus on clinical trials. Expert Opin Pharmacother 2006 Apr;7(5):575-81.

33. Leonhardt A, Dahlen G, Renvert S. Five-year clinical, microbiological, and radiographical outcome following treatment of peri-implantitis in man. J Periodontol 2003;74:1415-1422.

34. Mostafa TM, El-Sheikh MM, Abd El-Fattah F. Implantconnected versus tooth-connected implant-supported partial dentures: 2-year clinical and radiographic comparative evaluation. Int $\mathrm{J}$ Periodontics Restorative Dent 2015;35:335-343.

35. Tavassoli S, Yamalik N, Caglayan F, Caglayan G, Eratalay $\mathrm{K}$. The clinical effects of nifedipine on periodontal status. Journal of Periodontology 1998;69(2):108-112.

36. Srivastava AK, Kundu D, Bandyopadhyay P, Pal AK. Management of amlodipine-induced gingival enlargement: 
series of three cases. Journal of Indian Society of Periodontology 2010;14(4):279-281.

37. Etoiz ME, Carranza FA. The Gingiva. In: Carranza FA. and Newman MG.ed. Clinical Periodontology. Philadelphia: W.B. Saunders Company. 1996; chapter 1.

38. Leonhardt A. Putative periodontal pathogens on titanium implants and teeth in experimental gingivitis and periodontitis in beagle dogs. Clin Oral Implts Res 1992; 3:112-119.

39. Carranza F, Newman M. Clinical periodontolgy, 8th edition. W.B. Saunders Co. 1996.

40. Seymour RA, Ellis JS, Thomson JM, Monkman S, Idle JR. Amlodipine-induced gingival overgrowth. J Clin Periodontol 1994;21:281-3.

41. Prisant L, Herman W. Calcium channel blocker induced gingival overgrowth. J Clin Hypertens (Greenwich). 2002 Jul-Aug;4(4):310-1.

42. Visser A, Gerr M, Henny J, et al. Mandibular overdentures supported by two or four endosseous implants: A 5-years prospective study. Clin Oral Imp Res 2005;16:19-25.

43. Rabel A, Kohler SG, Schmidt-Westhausen AM. Clinical study on the primary stability of two dental implant systems with resonance frequency analysis. Clinical Oral Investigations 2007;11:257-265.
44. Atsumi M, Park SH, Wang HL. Methods used to assess implant stability: current status. Int. J. Oral Maxillofac. Implants 2007;22:743-754.

45. Sjoström M, Lundgren $\mathrm{S}$, Nilson $\mathrm{H}$, Sennerby L. Monitoring of implant stability in grafted bone using resonance frequency analysis. A clinical study from implant placement to 6 months of loading. International Journal of Oral and Maxillofacial Surgery 2005;34:45-51.

46. Miyata T, Kobayashi Y, Araki H, Ohto T, Shin K. The influence of controlled occlusal overload on peri-implant tissue. Part 3: A histologic study in monkeys. Int J Oral Maxillofacial 2000;15:425- 431.

47. Albrektsson T, Jansson T, Lekhalm U. Osseointegrated dental implants. Dental clinics North Am 1986; 30:151.

48. Adell R, Lekholm U, Rockier B Branemark PI. A 15 years study of osseointegrated implants in the treatment of edentulous jaw. Int J Oral Surgery 1981;10:387.

49. Albrektsson T, Zarb G, Worthington P, Eriksson A. The long-term efficacy of currently used dental implants: A review and proposed criteria of success. Int $\mathrm{J}$ Oral Maxillofac Implants 1986;1:11-25.

50. Al-Juboori MJ, Bin Abdulrahaman S, Jassan A. Comparison of flapless and conventional flap and the effect on crestal bone resorption during a 12-week healing period. Dent Implantol Update. 2012; 23: 9-16. 